\title{
Analysis of the Temporal and Seasonal Patterns of Maternal Mortality Ratio in Yenagoa, Bayelsa State of Nigeria
}

\author{
OMIDIJI, Adedoyin Oluwatoyin ${ }^{1 *}$, AKPOGHOMEH Osi S. ${ }^{2}$ \\ ${ }^{1}$ Department of Geography and Environmental Management, Faculty of Social Sciences, Niger Delta \\ University, Bayelsa State. Nigeria \\ ${ }^{2}$ Department of Geography and Environmental Management, Faculty of Social Sciences, University of Port \\ Harcourt. Rivers State. Nigeria
}

"Corresponding Author: Omidiji, Adedoyin Oluwatoyin, Department of Geography and Environmental Management, Faculty of Social Sciences, Niger Delta University, Bayelsa State, Nigeria. Email: doyinomidiji@yahoo.com

\begin{abstract}
The study analyzed the temporal and seasonal patterns of maternal mortality (both levels and ratios) in Yenagoa, the capital city of Bayelsa State, Nigeria. The objectives are to determine the levels and ratios of maternal mortality per month and per season over 8 years period (2010 to 2017). Data were collected from primary and secondary sources. A major tertiary hospital was used for this work based on its function and accessibility to women. Data were collected from the hospital records and was updated with the case folder. Both descriptive and inferential statistics were employed to analyze the data. The study revealed that the year 2015 witnessed the highest maternal mortality ratio of 1445.09 per 100,100 livebirth in Bayelsa state. Maternal mortality level was 10, while the number of livebirth was 692. The study also reviewed higher maternal mortality ratio during the wet season (1031.25 than dry season (961.87).Results further showed that there is no significant difference in maternal mortality ratio between the two seasons in the study area. Empirical results show Mann Whitney test 13.0032, and p-value of 0.619 was obtained (p>0.05), at $5 \%$ significant level, meaning that there is no significant difference in maternal mortality ratio between wet and dry season in the study area.
\end{abstract}

Keywords: Maternal, Mortality, Ratio, level, Temporal, Seasonal

\section{INTRODUCTION}

The impacts of mortality on the population structures, composition, and development of the economy cannot be emphasized. It is age and sex selective, it is high among infants, from 0-1 year, 1-5 years and at older ages. It is higher among women within (15-49) years old which coincides with their reproductive years and it is generally referred to as maternal mortality. (Okigbo, Adegoke \& Olorunsaiye, 2017; Waugh, 2014) ${ }^{1}$

However WHO (2014) $)^{2}$ and ISCDHP $(1992)^{3}$, gave a more refined definition and meaning to maternal death. In their words, maternal mortality "is the death of women while pregnant or within 42 days of termination of pregnancy irrespective of the duration and site of the pregnancy from any cause related to, or aggravated by the pregnancy or its management but not from accidental or incidental causes". The world's greatest concern today is the reduction in maternal mortality apparent by its frequent appearance in most development goals and its inclusion in the defunct millennium development goal (MDG) and sustainable development goal (SDGs). Despite all these efforts, the ratio of maternal mortality is still rated high in Nigeria. (Adam Franz-Vasdeki; 2012 ${ }^{4}$; Saraki, 2008 Rosenfield, Min \& Freeman, $2007^{6}$ ).

Several attempts have been made in the area of maternal health services to achieve permanent solution to the maternal and infant mortality ravaging the country.

Efforts include: clamoring for reproductive rights of women in Nigeria, Safe Motherhood Initiative, Midwives Scheme of the MDGs, that includes training and re-training of nurses and midwives in reproductive health-care and services, among others (United States Agency for International Development, $2009^{7}, \mathrm{WHO}, 2013^{8}$ ). In spite of all these programmes, the challenge has been the same, and this could be considered as a demographic outrage especially in Nigeria. 
One of the factors that can have significant impact on maternal mortality is high rate of poverty in a society. Poverty in terms of availability of amenities, adequate supply of power and water, school enrolment, low female education, no or little income of women.(Lanre-Abass, 2008) ${ }^{9}$. Yenagoa has been chosen for this study due to the prevalence high ratio of poverty, underdevelopment, early marriage/cohabitation, inadequate access to social amenities. All these indices add to the increasing ratio of maternal mortality in the area. Previous studies on maternal mortality in Nigeria concentrated on the causes of maternal mortality in several parts of Nigeria, moreover, most of the studies focused on village or town (Omidiji and Akpoghomeh, 2019 ${ }^{10}$; ; Audu , Takai and Bukar,2010 ${ }^{11}$; Oladapo, Lamina and Fakoya, 2006 ${ }^{12}$; Aniefiok, Umoiyobo ,Edem and Saturday , $2005^{13}$; Aboyeji A.P. $1988^{14}$ ) There is no work on temporal and seasonal variation in maternal mortality in Yenagoa. This constitutes a gap in the literature that this present study seeks to fill.

Therefore the aim of this research is to analyze the seasonal pattern of maternal mortality in Yenagoa Bayelsa State of Nigeria. The objectives are to determine the maternal mortality in levels and in ratio over the years, months, and between the seasons of the year.

\section{Materials AND MethodS}

\subsection{Research Design}

Cross sectional research design was employed in this study with retrospective study of maternal mortality

\subsection{Sources of Data}

The sources of data were primary in nature as information needed was collected from the hospital register. Secondary data were sourced from journals and Government establishment's documents

\subsection{Data Collection}

Accessibility and functions of the hospital was the major reason for choosing the hospital among other ones in Yenagoa. Data on the year and month of death were obtained directly from the death register, and updated with information on the patient's folder. Deaths that occurred from November to February were classified under Dry season, while the deaths occurring from April to October were classified under wet season. The data collection took almost a year to be completed.

\section{RESULTS AND DISCUSSION}

Data was discussed descriptively with tables, frequency counts, percentages, and the values depicted in line graphs. Hypothesis was analyzed using SPSS version 22.0. Data on maternal mortality level and number of live birth was got from 2010 to 2017. Over the 8 years period, there were 60 incidences of maternal mortality, 9209 live births and maternal mortality rate (MMR) was 651.16, with a mean MMR of 672.6. (See table 1). The MMR was calculated using the formula below:

MMR $=\frac{\text { No of maternal mortality }}{\text { No of livebirth }} \times 100,000 \quad=651.16$ per 100,000 livebirth.

MMR has been fluctuating over the years, despite the fact that number of live birtsh (692) was low in 2015, the incidence of maternal death was high (10 cases of maternal death). The year 2015 witnessed high MMR in Bayelsa state. The rise in maternal mortality ratio in 2015 was due to the fact that government shifted attentions to other public health matters in the area, like Ebola, monkey pox and other health issues that were claiming lives instantly. However, the MMR reduced drastically to 202.43 in 2016. In 2017, MMR increased again to 645.16 per 100,000 livebirth. The total maternal mortality ratio over the period is 651.16 per 1,000,000 livebirth.

Table1: Levels and ratios of maternal mortality in Bayelsa State

\begin{tabular}{|l|l|l|l|}
\hline \multicolumn{1}{|c|}{ Years } & Maternal Mortality & Number of Livebirth & \multicolumn{1}{c|}{ MMR per 100,000 } \\
\hline 2010 & 9 & 1190 & 756.30 \\
\hline 2011 & 11 & 1534 & 717.08 \\
\hline 2012 & 9 & 1528 & 589.01 \\
\hline 2013 & 10 & 1434 & 697.35 \\
\hline 2014 & 3 & 913 & 328.59 \\
\hline 2015 & 10 & 692 & 1445.09 \\
\hline
\end{tabular}


Analysis of the Temporal and Seasonal Patterns of Maternal Mortality Ratio in Yenagoa, Bayelsa State of Nigeria

\begin{tabular}{|l|l|l|l|}
\hline 2016 & 2 & 988 & 202.43 \\
\hline 2017 & 6 & 930 & 645.16 \\
\hline Total & $\mathbf{6 0}$ & $\mathbf{9 2 0 9}$ & $\mathbf{6 5 1 . 1 6}$ \\
\hline
\end{tabular}

Source: Researcher's fieldwork, 2018

Tables 2 and Figure 1 show the mean temporal pattern of MMR (in years) in Bayelsa state. The mean MMR of 1382.7 per 100,000 livebirth in 2015 was very high. The lowest mean MMR was obtained in 2014, with 213.6 per 100,000 livebirth. The region experienced two peak periods of MMR. It was first high in 2015(1382.7 per 100,000 livebirth) it reduced drastically to 193.03 per thousand livebirth, in 2014 and increased again to 776.38 per thousand livebirth in year 2017

Table2: Temporal patterns of Mean MMR in Bayelsa State (years)

\begin{tabular}{|l|l|l|l|l|}
\hline \multicolumn{1}{|c|}{ Year } & \multicolumn{1}{|c|}{ Mean } & \multicolumn{1}{c|}{ std dev } & \multicolumn{1}{c|}{ Minimum } & \multicolumn{1}{c|}{ Maximum } \\
\hline 2010 & 718.7 & 563.5 & 0.0 & 1470.6 \\
\hline 2011 & 730.3 & 846.4 & 0.0 & 3100.8 \\
\hline 2012 & 592.4 & 575.1 & 0.0 & 1388.9 \\
\hline 2013 & 637.4 & 821.4 & 0.0 & 2419.4 \\
\hline 2014 & 213.6 & 388.4 & 0.0 & 943.4 \\
\hline 2015 & 1382.7 & 1936.2 & 0.0 & 5454.5 \\
\hline 2016 & 160.9 & 394.8 & 0.0 & 1250.0 \\
\hline 2017 & 776.4 & 1115.0 & 0.0 & 3448.3 \\
\hline
\end{tabular}

Source- Researcher's fieldwork, 2018

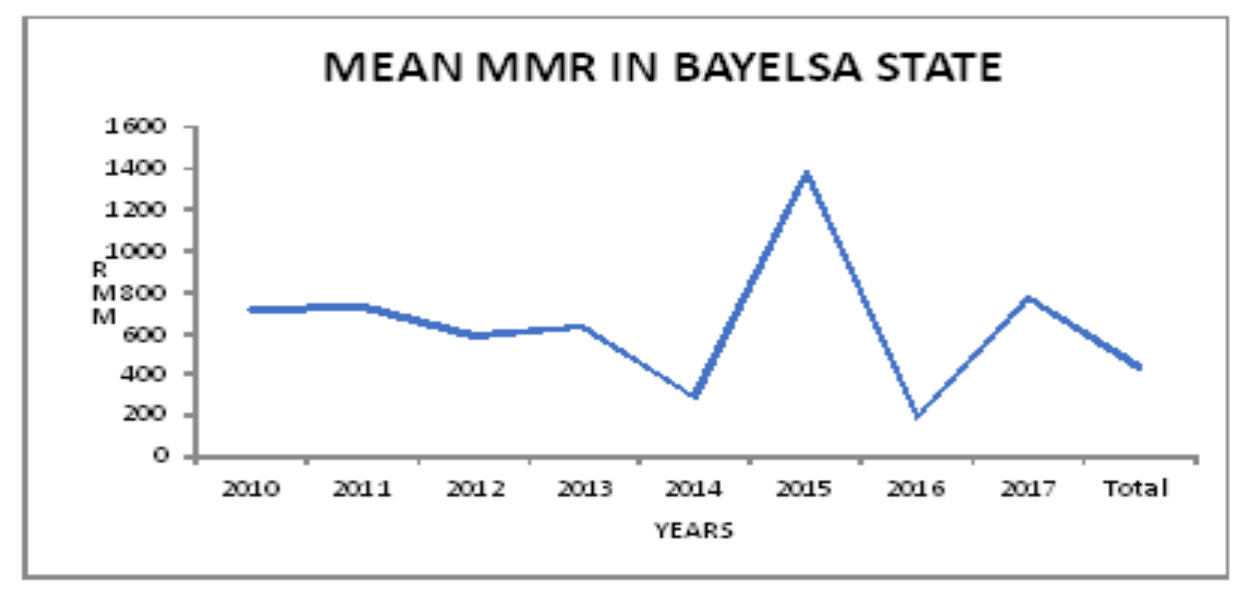

Figure1: Mean maternal mortality ratio in Bayelsa state (years)

Source- Researcher's fieldwork, 2018

In relation to months of the year (table 3.and figure 2), the highest mean MMR per month was reported in the month of April, with MMR of 1217.1 per thousand livebirth), while the lowest was recorded in the month of September, with mean MMR of 105.0 per thousand livebirth.

Table3: Temporal patterns of maternal mortality in Bayelsa State (Monthly Basis)

\begin{tabular}{|l|l|l|l|l|}
\hline \multicolumn{1}{|c|}{ Month } & \multicolumn{1}{|c|}{ Mean } & \multicolumn{1}{c|}{ Minimum } & \multicolumn{1}{c|}{ Maximum } \\
\hline January & 714.6 & 1218.2 & 0 & 3448.276 \\
\hline February & 577.1 & 632.9 & 0 & 1449.275 \\
\hline March & 1189.0 & 1607.2 & 0 & 5000 \\
\hline April & 1217.1 & 1817.0 & 0 & 5454.545 \\
\hline May & 553.7 & 700.1 & 0 & 1639.344 \\
\hline June & 1064.8 & 858.7 & 0 & 2419.355 \\
\hline July & 550.8 & 660.8 & 0 & 1680.672 \\
\hline August & 420.2 & 620.2 & 0 & 1587.302 \\
\hline September & 105.0 & 297.1 & 0 & 840.3361 \\
\hline October & 351.4 & 487.2 & 0 & 1020.408 \\
\hline November & 874.9 & 1113.2 & 0 & 3100.775 \\
\hline December & 199.9 & 372.1 & 0 & 869.5652 \\
\hline
\end{tabular}

Source- Researcher's fieldwork, 2018

International Journal of Research in Geography (IJRG) 


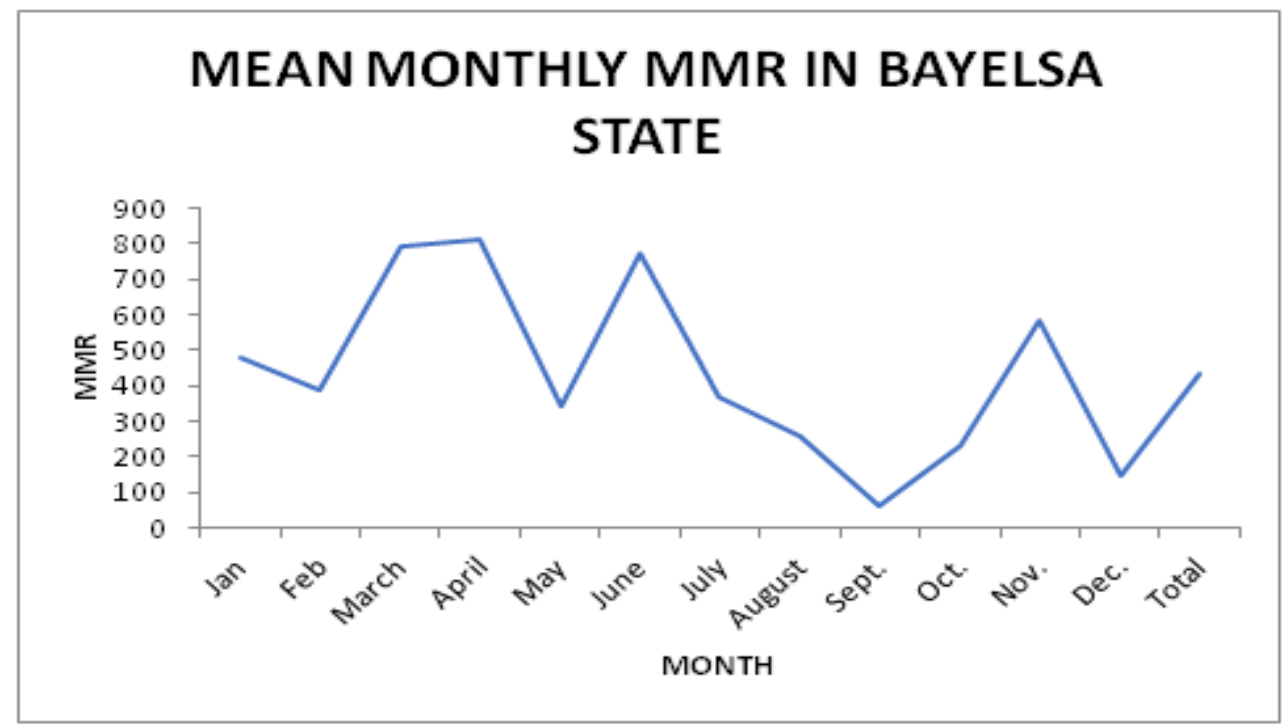

Figure2: Mean MMR in Bayelsa State (Months)

Source- Researcher's fieldwork, 2018

Tables 4 reveals MMR between the dry season (November to February) and wet season (March to October). Result shows that in Bayelsa State, the average MMR during the dry wet season was obtained to be 961.9 per thousand livebirth, while in wet season, it was 1031.3 per 100,000 livebirth. The result reveals higher MMR during wet season than dry season

Table4: Maternal mortality ratios between seasons in Bayelsa State

\begin{tabular}{|l|l|l|l|l|l|}
\hline \multicolumn{2}{|c|}{} & $\mathrm{n}$ & Mean & Std. Deviation & Std. Error Mean \\
\hline & Wet season & 8 & 1031.25 & 367.98 & 130.10 \\
\cline { 2 - 6 } & Dry Season & 4 & 961.88 & 330.41 & 165.20 \\
\hline
\end{tabular}

Source- Researcher's fieldwork, 2018

The work has revealed the distribution of MMR and the season in each year from 2002 to 2017. It was observed that the distribution of MMR is the same across the categories of season from 2002 to 2017.

\subsection{Hypothesis Testing}

Ho: There is no significant difference in maternal mortality ratio between the two seasons in the study area.

Result in Table 5 shows maternal mortality ratio (MMR) between dry and wet season in the study area. In Bayelsa State, the result Mann- Whitney statistic statistics yielded 13.0032, and p-value of 0.619 was obtained $(p>0.05)$ meaning that there is no significant difference in maternal mortality ratio between the two seasons in the study area.

Table5: Mann- Whitney (Non- Parametric test) result summary comparing maternal mortality ratio (MMR) between wet and dry season

\begin{tabular}{|l|l|l|l|l|l|l|}
\hline State & Season & Mean Rank (MR) & Sum of Rank & Mann- Whitney Statistic & p-value & Remarks \\
\cline { 1 - 6 } Bayelsa & Wet & 6.88 & 55 & 13 & 0.61 & NS \\
\hline & Dry & 5.75 & 23 & & & \\
\hline
\end{tabular}

NS- not significant at $5 \%(\mathrm{p}>0.05)$.

Source- Researcher's fieldwork, 2018

$\mathbf{H o}_{2}$ : There is no significant difference in the incidence of maternal mortality between the two seasons of the year.

Table 6 shows 67 cases of maternal mortality in Bayelsa State during wet season and 26 cases during dry season with $\chi^{2}$ calculated. $=18.08 ; \chi^{2}$ - Critical. $=3.84$, meaning that $\chi^{2}$ calc. $>\chi^{2}$ - crit.). This means that incidence of maternal mortality was significantly higher during wet season the dry season. 
Table6: Chi-Square result summary showing differences in the maternal mortality levels between wet and dry season

\begin{tabular}{|l|l|l|l|l|l|}
\hline Season & Wet & Dry & $\chi^{2}$ - calc. & Df & $x^{2}$-crit. \\
\hline Bayelsa $(\mathrm{n}=93)$ & $\begin{array}{l}67 \\
(46.5)\end{array}$ & $\begin{array}{l}26 \\
(46.5)\end{array}$ & 18.08 & 1 & 3.84 \\
\hline
\end{tabular}

Values in the parentheses are the expected frequencies, $\mathrm{df}=$ degrees of freedom,

**significant at $5 \%$

Source- Researcher's fieldwork, 2018

Thus, this study shows that there are variations in MMR over the past eight years and over the months. These findings align with the submission of Abe and Omo-Aghoja (2008) ${ }^{15}$, whose work revealed that temporal variations in maternal mortality ratio existed in Benin City. Their work shows a progressive increase in maternal mortality ratios over 10 years period. Furthermore, the findings from this work, support that of Izugbara, Wekesah and Adedini, (2016) ${ }^{16}$, they recorded MMR of 560 per 100,000 livebirth for Nigeria and posited that, MMR is generally high in Nigeria and the average MMR for Sub Sahara African was put at 510 per 100,000 livebirth. However, the MMR in Yenagoa could be considered as high in line with the work of Adam and franz-vasdeki $(2012)^{17}$, who stated categorically that maternal mortality ration is considered to be high is the ratio is 400 and above

\section{CONCLUSION}

The temporal and seasonal patterns of maternal mortality have been analyzed, maternal mortality ratio varied over the years, months and the two seasons. It was revealed that when government shifted her attention to other public health issues, there was an upsurge in maternal mortality rate. Hence, the researchers are agitating for continuous and intensified support from the Government and other stakeholders, in other to meet up the target of the Sustainable Development Goal before 2030 and to bring maternal mortality rate to the barest minimum.

\section{REFERENCES}

[1] Okigbo, C. C., Adegoke, K. K. \& Olorunsaiye, C. Z. (2017). Maternal and Child Health in Africa for Sustainable Development Goals (SDGs) Beyond 2015, An International Journal for Research, Policy and Practice, 12,(6)Issue 6

[2] World Health Organization (2014 ).Trends in maternal mortality 1990 to 2013.Estimates by WHO,

[3] International Statistical Classification of Diseases and Related Health Problems (ISCDRHP (1992).Tenth Revision. Vol. 1: Tabular list. Vol. 2: Instruction manual. Geneva: WHO; 1992

[4] Adam Taghreed And Franz-Vasdeki- Jennifer, (2012). Success Factors For Women's And Children's Health: A Quantitative Mapping Of Trends In Reductions Of Maternal And Child Mortality In The High Mortality burden. December 17, 2012 http://www.who.int/pmnch/ knowledge/publications/adam.pdf

[5] Saraki T (2008). Nigeria: Maternal Health - More Than Just Reproductive Health. This Day. http://allafrica.com/stories/200807090631.htmlRetrieved on 03/12/2017

[6] Rosenfield A, Min C, Freedman L (2007). Making motherhood safe in developing Countries. N ngl J Med; 356:1395-1397.

[7] United States Agency for International Development.(2009). Country Health Statistical Report Nigeria Country Health Statistical Reports Analysis, Information Management and Communication Activity (AIM) Project United States Agency for International Development. USAID, May 2009.

[8] World Health Organisation (2013). Family Planning. http://www.who.int./medicare/ factsheets/ fs351/en.

[9] Lanre -Abass, B.A. (2008) Int J Equity Health 7:11 https://doi.org/10.1186/1475- 9276-7-11, https:// link.springer.com/article/10.1186/1475-9276-7-11

[10] Omidiji A.O. and Akpoghomeh,O.S. (2019) . The causes of maternal mortality in the Core Niger Delta Region of Nigeria. International Journal of Innovative Healthcare Research, 7(2):6-15, April-June, http://seahipaj.org/journals-ci/june-2019/IJIHCR/full/IJIHCR-J-2-2019.pdf

[11] Audu BM, Takai UI, Bukar M.(2010). Trends in maternal mortality at University of Maidugiri Teaching Hospital, Maidugiri, Nigeria - A five year review. Niger Med J; 51:147-51.

[12] Oladapo T. Olufemi , Lamina A. Mustafa and Fakoya A.Tuminu (2006).Maternal deaths in Sagamu in the new millennium: a facility-based retrospective analysis. BMC Pregnancy and Childbirth20066:6. https://doi.org/10.1186/1471-2393-6-6 
[13] Aniefiok J Umoiyoho, Aniekan M Abasiattai, Edem J Udoma, Saturday J Etuk. (2005) Community perception of the causes of maternal mortality among the Annang of Nigeris's South -East coast. Tropical Journal of Obstetrics and Gynaecology Vol. 22(2) 2005: 189-192,

[14] Aboyeji A.P. (1998). Trends in maternal mortality in Ilorin. International Journal of Gynecology and Obstetrics .Nov:63(2):183-4

[15] Abe EgheL \& Omo-Aghoja Lawrence, (2008). Maternal Mortality at the Central Hospital, Benin City: A Ten Year Review . African Journal of Reproductive Health 12 [3], 17-26

[16] Izugbara, C.O., Wekesah, F. M. \&Adedini, S. A. (2016). Maternal Health in Nigeria: A Situation Update. African Population. and Health Research Center (APHRC), Nairobi, Kenya

[17] Adam Taghreed and Franz-Vasdeki- Jennifer, (2012). Success Factors for Women's and Children's Health: A Quantitative Mapping of Trends in Reductions of Maternal and Child Mortality in the High Mortality burden. December 17, 2012 Http://Www.Who.Int/Pmnch/Knowledge/Publications/ Adam.Pdf

\section{AUTHORS' BIOGRAPHY}

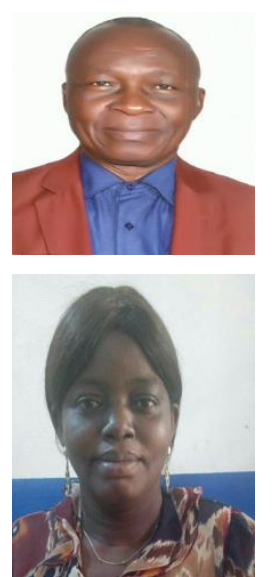

AKPOGHOMEH , Osi S. is a Professor of Transport and Population Geography. $\mathrm{He}$ is currently at the Department of Geography and Environmental Management, University of Port Harcourt, Port Harcourt, Rivers State. Nigeria.

married and blessed with children.

Citation: Omidiji, Adedoyin Oluwatoyin \& Akpoghomeh Osi S. "Analysis of the Temporal and Seasonal Patterns of Maternal Mortality Ratio in Yenagoa, Bayelsa State of Nigeria”. International Journal of Research in Geography. vol 5, no. 2, 2019, pp. 13-18. doi: http://dx.doi.org/10.20431/2454-8685.0502002.

Copyright: (C) 2019 Authors. This is an open-access article distributed under the terms of the Creative Commons Attribution License, which permits unrestricted use, distribution, and reproduction in any medium, provided the original author and source are credited. 